\title{
Screening for Salt Tolerance in Eight Halophyte Species from Yellow River Delta at the Two Initial Growth Stages
}

\author{
Liu Xianzhao,, ${ }^{1,2,3}$ Wang Chunzhi, ${ }^{2}$ and Su Qing ${ }^{4}$ \\ ${ }^{1}$ College of Architecture and Urban Planning, Hunan University of Science and Technology, Xiangtan 411201, China \\ ${ }^{2}$ College of Geography and Planning, Ludong University, Yantai 264025, China \\ ${ }^{3}$ Department of Geography, Linyi University, Linyi 264000, China \\ ${ }^{4}$ College of Life Science, Hunan University of Science and Technology, Xiangtan 411201, China
}

Correspondence should be addressed to Liu Xianzhao; xianzhaoliu@sina.com

Received 29 May 2013; Accepted 17 June 2013

Academic Editors: N. Hulugalle, C. H. Kao, and M. Zhou

Copyright (C) 2013 Liu Xianzhao et al. This is an open access article distributed under the Creative Commons Attribution License, which permits unrestricted use, distribution, and reproduction in any medium, provided the original work is properly cited.

\begin{abstract}
Screening of available local halophytes for salinity tolerance is of considerable economic value for the utilization of heavy saltaffected lands in coastal tidal-flat areas and other saline areas. In this study, the germination and seedling pot experiments on salt tolerance of eight halophytic species from Yellow River Delta, China, at seven $\mathrm{NaCl}$ concentrations (0, 50, 100, 150, 200, 250, and $300 \mathrm{mM}$ ), were conducted at both growth stages. Results showed that germination rate and germination index decreased with an increase in $\mathrm{NaCl}$ concentration. The higher germination rates were obtained from Tamarix chinensis and Suaeda salsa seeds exposed to $0 \sim 200 \mathrm{mM} \mathrm{NaCl}$. At the seedling stage, the salt tolerances of eight halophytes were also different from each other. Tamarix chinensis had significantly greater fresh biomass and plant height in relative terms than the others in all salt treatments. The order of the relative growth yield in seedling was Tamarix chinensis $>$ Suaeda salsa $>$ Salicornia europaea $>$ Limonium bicolor $>$ Atriplex isatidea $>$ Apocynum venetum $>$ Phragmites australis $>$ Sesbania cannabina. The comprehensive analysis showed that Tamarix chinensis had the highest tolerance to salt, followed by Suaeda salsa, and the salt tolerance of Sesbania cannabina was the lowest.
\end{abstract}

\section{Introduction}

Soil salinization is one of the most serious impediments to agricultural production both in China and the other regions of the world $[1,2]$. According to statistics, there is about $9.54 \times 10^{8} \mathrm{hm}^{2}$ of saline soil worldwide, and seven percent of the land surface and five percent of cultivated lands are affected by salinity $[3,4]$. China has all kinds of saline soils with a total area of about $0.99 \times 10^{8} \mathrm{hm}^{2}$. In the Yellow River Delta alone, there is approximately $44.3 \times 10^{4} \mathrm{hm}^{2}$ of seashore salinized tidal flat, including heavily salinized soil (soil salinity is over $0.6 \%$ ) and saline-alkaline bare land with an area of $23.63 \times 10^{4} \mathrm{hm}^{2}$. And this number continues to grow at a rate of $2.2 \times 10^{4} \mathrm{hm}^{2}$ per year due to a variety of natural and human activities [5-7]. On these saline lands, it is not suitable for growth of traditional crops because of extreme salinity and other adverse factors. If plant salt tolerance cannot be improved, then vast amounts of soils may be left uncultivated. This will severely threaten the national food security and biomass energy production.

In recent years the development thinking of solonchak agriculture is brought up at home and abroad. Namely, salinized soils can be utilized through the transgenic technology or the breeding of salt-tolerant plants, which may successfully maintain a relatively reasonable yield and an increased growth on salt-affected soils. And then some approaches to overcome the salinity problem have been put forward by various plant scientists $[1,2,8]$. For example, large scale soil was ameliorated to meet the needs of plant growth by either altering farming practices to prevent soil salinization or implementing schemes to remediate salinized soils. One of the most feasible and economic paths, which is of prime 
importance, is the screening of available local halophytes for salinity tolerance, despite its limitation of time required and environment dependence.

Halophytes are plants, which are able to grow or survive in saline conditions and have considerable importance as food, forage, and material source for biofuel [9]. Cultivation of halophytes or salt-tolerant plants on the salt soil in some cases would spare arable land and fresh water for conventional agriculture. Despite strong adaptations to saline environments, halophytes are sensitive to salt stress, like many other traditional crops, and may not sustain good growth or yield when they are grown in soils with high salt concentrations $[10,11]$. In recent years, extensive research on plant screening for salt tolerance has been conducted, with the aim of providing a relatively tolerant cultivar, but these researches mainly focused on conventional crops, screening criteria, and methods for plants salt tolerance [1, 12-15]. Unfortunately, there are few investigations about the screening of available halophyte species and their responses to heavy saline conditions.

Keeping this in mind, the work presented here was carried out to examine the salinity tolerance of eight local halophytes by germination and pot experiments when exposed to different $\mathrm{NaCl}$ concentrations. The aim of this study was to determine how far the ecological amplitude, in relation to salt, of a range of halophyte species may be restricted by their inability to evolve salt tolerance and finally screen the most adaptive salt-tolerant halophytes which can grow well on the heavy salt soils.

\section{Materials and Methods}

The 8 halophyte species (Tamarix chinensis, Suaeda salsa, Atriplex isatidea, Apocynum venetum, Sesbania cannabina, Salicornia europaea, Phragmites australis, and Limonium bicolor) were used in this study. The seed material was collected during October 2010 from Halophytes Garden of Dongying in the Yellow River Delta, China, and stored for four months at room temperature $\left(22^{\circ} \mathrm{C}\right)$ and $50 \%$ relative humidity. Prior to experimentation, seed samples were surface sterilized using 5\% sodium hypochlorite solution for five minutes and thoroughly rinsed with distilled water.

2.1. Germination Experiment. The germination experiment was conducted in a growth chamber at $26 \pm 2^{\circ} \mathrm{C}$, with $12 \mathrm{~h}$ day length, at a light intensity of $36 \mathrm{Wm}^{-2}$ and relative humidity of $76 \% .30$ surface sterilized seeds of each halophyte were placed on moistened filter paper in a $9 \mathrm{~cm}$ plastic Petri dish. The plastic Petri dishes were arranged in a completely randomized design, with five replicates, seven salt treatments $(0,50,100$, $150,200,250$, and $300 \mathrm{mM} \mathrm{NaCl}$ ), and the 8 halophyte species mentioned above. $5 \mathrm{~mL}$ of appropriate treatment solution was applied on alternate days to each Petri dish after rinsing out the previous solution. A seed was considered to have germinated when both plumule and radicle had emerged $\geq 2 \mathrm{~mm}$. The number of germinated seeds was counted daily for 7 days. The rate of germination was expressed a percentage of the number of germination seeds divided by the number of tested seeds for each treatment. The germination index (GI) was estimated using a modified Timson index [16] of germination velocity, GI $=\sum G / t$ (where $G$ is the number of seed germination every day, and $t$ is the corresponding number of days for germination test). The relative germination index (RGI) is expressed as a ratio of germination index under salt stress to germination index in control treatment.

2.2. Seedling Experiment. Seedling Experiments for salt tolerance were conducted to evaluate the effects of salinity on halophyte growth in a glasshouse at $24 \pm 3^{\circ} \mathrm{C}$ day temperature and $12 \pm 1^{\circ} \mathrm{C}$ night temperature. For each halophyte, twenty to thirty seeds, depending upon 8 halophytic species, were sown in a $3 \mathrm{~L}$ PVC (polyvinyl chloride) pot with a mixture containing $70 \%$ perlite and $30 \%$ dry sand. After two weeks, seedlings were thinned to leave seven uniform and healthy seedlings in each pot. All the pots were irrigated for one week with Hoagland solution every alternate day. The concentrations of $\mathrm{NaCl}$ used were exactly the same as we used in the germination experiment, namely, $0,50,100,150$, 200, 250, and $300 \mathrm{mM}$. The experiment was laid out in a completely randomized design with five replications in each treatment. $\mathrm{NaCl}$ treatment was applied to 3-week-old plants and lasted for 5 weeks. The salt concentration was increased in aliquots of $25 \mathrm{mM}$ on alternate days until the appropriate salt treatment was reached. Plants were watered twice a day with about $50 \mathrm{~mL}$ solution applied each time per pot. The symptoms of plant injury at salt stress were observed at any time during the course of the experiment. After 35 days of $\mathrm{NaCl}$ treatment, two measurements were undertaken in each treatment for both plant height and fresh weight of aboveground biomass. Salt tolerance of plant has been assessed by measuring the relative growth rate and the salt damage rate, which were expressed as follows:

relative growth rate

$$
=\frac{\text { plant growth at salt concentration }}{\text { plant growth at control treatment }} \times 100 \% \text {, }
$$

salt-injury rate

$$
\begin{aligned}
= & \frac{\text { number of plants with salt-injury symptoms }}{\text { total number of plants }} \\
& \times 100 \% \text {. }
\end{aligned}
$$

2.3. Statistical Analysis. Data were analyzed statistically using a one-way analysis of variance (ANOVA), linear regression, and correlation analysis, and the means of each treatment were analyzed by Duncan's multiple range test. All statistical methods were performed with SAS software [17].

\section{Results}

3.1. Effect of Different Concentrations of $\mathrm{NaCl}$ on the Seed Germination. One-way ANOVA of the data for germination rate of the 8 halophyte seeds indicated that salt treatment 
TABLE 1: Results of one-way ANOVA for germination rate of the eight species at different $\mathrm{NaCl}$ treatments.

\begin{tabular}{lcccc}
\hline Species & df & Mean square & $F$ & $P$ \\
\hline Sesbania cannabina & 6 & 16.63 & 21.48 & $<0.01$ \\
Limonium bicolor & 6 & 19.32 & 20.04 & $<0.01$ \\
Suaeda salsa & 6 & 31.32 & 27.08 & $<0.01$ \\
Tamarix chinensis & 6 & 38.14 & 19.16 & $<0.01$ \\
Apocynum venetum & 6 & 21.54 & 14.28 & $<0.01$ \\
Salicornia europaea & 6 & 14.45 & 33.87 & $<0.01$ \\
Phragmites australis & 6 & 15.76 & 18.93 & $<0.01$ \\
Atriplex isatidea & 6 & 41.46 & 30.37 & $<0.01$ \\
\hline
\end{tabular}

had a significantly adverse effect on total germination rate (Table 1). As the $\mathrm{NaCl}$ concentration increased, the eight species all exhibited a decreasing trend of germination rate (Figure 1). For example, compared with the control, the total germination rates of Suaeda salsa at 50, 100, 150, 200,250 , and $300 \mathrm{mM} \mathrm{NaCl}$ treatments were $94.5 \%, 87.2 \%$, $81.4 \%, 78.4 \%, 69.3 \%$, and $56.2 \%$ of the control, respectively. Although the germination of halophyte seeds was strongly inhibited when they were subjected to salt stress, the degree of inhibition differed markedly. The eight halophytic species tested in this study could be classified into three groups depending on their ability to germinate in saline medium. First group was the most salt tolerant and had the smallest degree of salt inhibition. These plants (Suaeda salsa, Tamarix chinensis, Apocynum venetum, and Salicornia europaea) in this group had higher final germination rate $(>80 \%)$ when the salinity was less than $100 \mathrm{mM} \mathrm{NaCl}$ and still had more than $40 \%$ of the germination rate even on the highest salinity condition (300 mM NaCl) (Figures 1(c) 1(d)). The second was the moderate tolerant halophytes, including Sesbania cannabina and Limonium bicolor. Their seeds also retained high germination rate at low saline $(\leq 50 \mathrm{mM} \mathrm{NaCl})$ and nonsalt treatments, whereas the germination rate decreased significantly at $150 \mathrm{mM} \mathrm{NaCl}$ (Figures 1(a) and 1(b)). The third was the least tolerant at the germination stage. The halophytes, Phragmites australis and Atriplex isatidea, each had the lowest germination rate as compared to the other six halophytes even if the $\mathrm{NaCl}$ concentration was very low, or under the without salinity conditions (Figures $1(\mathrm{~g})$ and $1(\mathrm{~h})$ ). This may be related to the lower viability of the two species.

Variance analysis of the data for GI also showed that salt treatment had a significant effect on germination of the eight species (Table 2). The GI had the same change trend with that of germination rate. As the salt concentration increased, the GI of the eight halophyte seeds gradually decreased (Table 3). In the eight species Tamarix chinensis under all $\mathrm{NaCl}$ treatments had the highest GI, followed by Suaeda salsa and Apocynum venetum. And when the salinity concentration was less than $150 \mathrm{mM}$, the GI of Tamarix chinensis was more than $84 \%$. However, the other five halophytes, Sesbania cannabina, Salicornia europaea, Phragmites australis, Atriplex isatidea, and Limonium bicolor, each showed a very poor GI (lower than $40.0 \%$ ) both in nonsalt and all salt treatments (Table 3). Among them, the GI of Phragmites australis and
TABLE 2: Results of one-way ANOVA for germination index of the eight species at different $\mathrm{NaCl}$ treatments.

\begin{tabular}{lcccc}
\hline Species & df & Mean square & $F$-value & $P$ value \\
\hline S. cannabina & 6 & 15.78 & 41.25 & $<0.001$ \\
L. bicolor & 6 & 13.32 & 84.16 & $<0.001$ \\
S. salsa & 6 & 16.89 & 89.56 & $<0.001$ \\
T. chinensis & 6 & 18.34 & 59.51 & $<0.001$ \\
A. venetum & 6 & 17.52 & 71.30 & $<0.001$ \\
S. europaea & 6 & 16.95 & 46.27 & $<0.001$ \\
P. australis & 6 & 14.35 & 21.31 & $<0.001$ \\
A. isatidea & 6 & 11.64 & 12.33 & $<0.05$ \\
\hline
\end{tabular}

Atriplex isatidea rapidly decreased to $0.1 \%$ and $1.7 \%$, respectively, at $250 \mathrm{mM} \mathrm{NaCl}$, and when the concentration of $\mathrm{NaCl}$ was over $200 \mathrm{mM}$, the germination of Sesbania cannabina and Limonium bicolor was completely inhibited (Table 3 ). The results indicated that there was tremendous difference in ability of halophytes to germinate in the presence of $\mathrm{NaCl}$ salinity.

From Table 4, it could be seen that the relative germination index had a significantly linear negative relationship with $\mathrm{NaCl}$ concentration (all $r<-0.9$, all $P \leq 0.01$ ), which again showed that salt treatment had a significantly adverse effect on germination of halophytic seeds. According to the linear regression equations listed in Table 4 and the method proposed by Bai et al. [18] and Zeng et al. [11], let the relative germination index be equal to $75 \%, 50 \%$, and $25 \%$ respectively; we could obtain the appropriate, critical, and limited values of salt concentration for germination of the eight halophyte seeds under salt stress conditions. Data in Table 4 demonstrated that at the germination stage, Tamarix chinensis was the most salt tolerant of all the tested halophyte seeds, which was consistent with the results observed in Figure 1.

\subsection{Effect of Different $\mathrm{NaCl}$ Treatments on the Growth of} Halophytes at the Seedling Stage. Analyses of variance of the data for relative growth for the eight halophytes showed that five weeks of salt treatment had a significant influence on growth characteristics measured (plant height $P \leq$ 0.01 ; above-ground biomass $P \leq 0.01$ ) at the seedling stage. As the salt concentration increases, the degrees of growth inhibition and salt-injury rate increase. High $\mathrm{NaCl}$ treatment $(\geq 200 \mathrm{mM})$ had an obviously adverse inhibition on all tested halophytes, with the relative growth rate (fresh weight of above-ground biomass and plant height) being fast reduced, and the salt-injury rate increased rapidly as the $\mathrm{NaCl}$ concentration increased above $150 \mathrm{mM}$ (Figures 2 and $3)$. For example, the seedlings of Sesbania cannabina and Phragmites australis were dying at $300 \mathrm{mM} \mathrm{NaCl}$ (Figure 2), and their salt-injury rates were drastically increased from 5.1\% (Sesbania cannabina) and 4.5\% (Phragmites australis) at $150 \mathrm{mM} \mathrm{NaCl}$ to nearly $100 \%$ at $300 \mathrm{mM} \mathrm{NaCl}$ (Figure 3), accompanied by death of individual whole plant.

However, when tested plants were under hyposaline, there were some differences in relative growth and salt-injury 


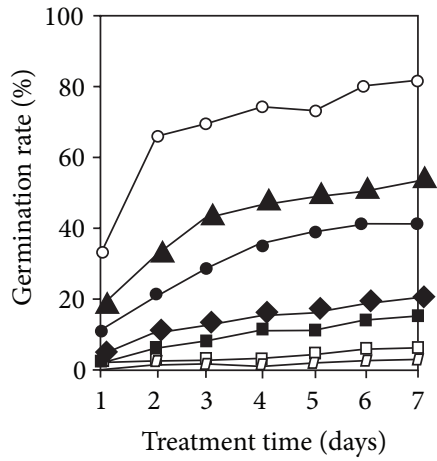

(a) Sesbania cannabina

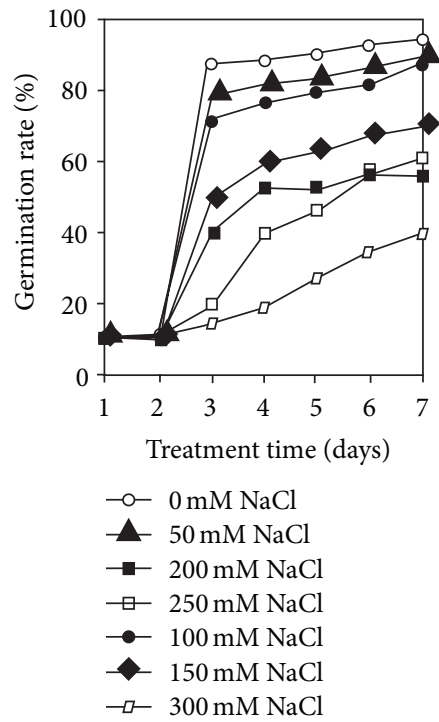

(e) Apocynum venetum

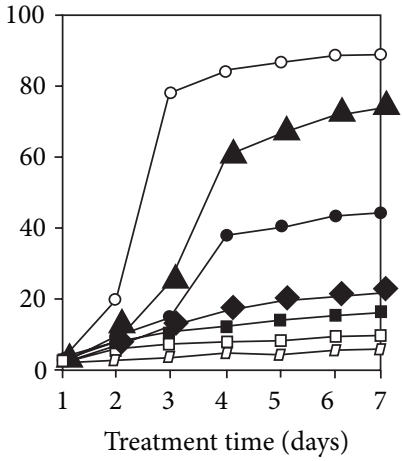

(b) Limonium bicolor
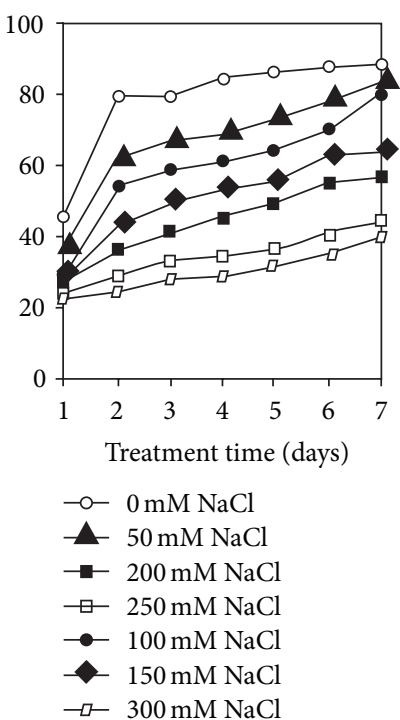

(f) Salicornia europaea

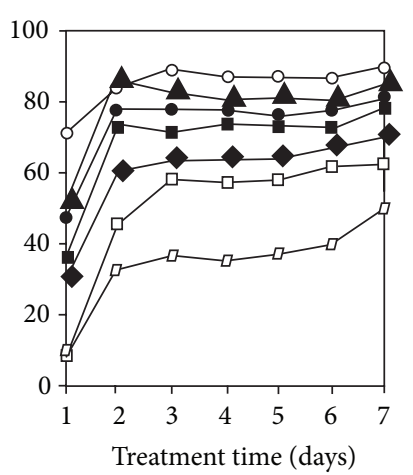

(c) Suaeda salsa

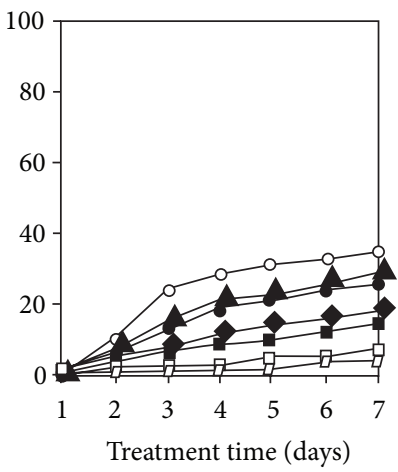

$\multimap 0 \mathrm{mM} \mathrm{NaCl}$

- $50 \mathrm{mM} \mathrm{NaCl}$

$\rightarrow-200 \mathrm{mM} \mathrm{NaCl}$

七- $250 \mathrm{mM} \mathrm{NaCl}$

$\rightarrow 100 \mathrm{mM} \mathrm{NaCl}$

- $150 \mathrm{mM} \mathrm{NaCl}$

$\rightarrow-300 \mathrm{mM} \mathrm{NaCl}$

(g) Phragmites australis

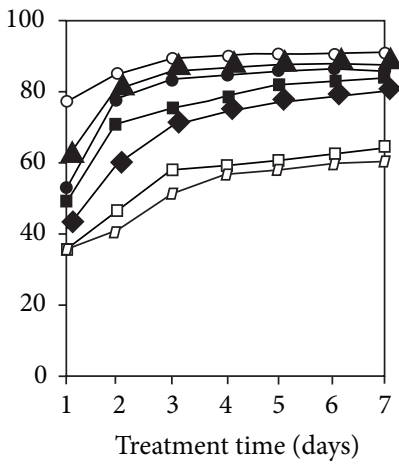

(d) Tamarix chinensis
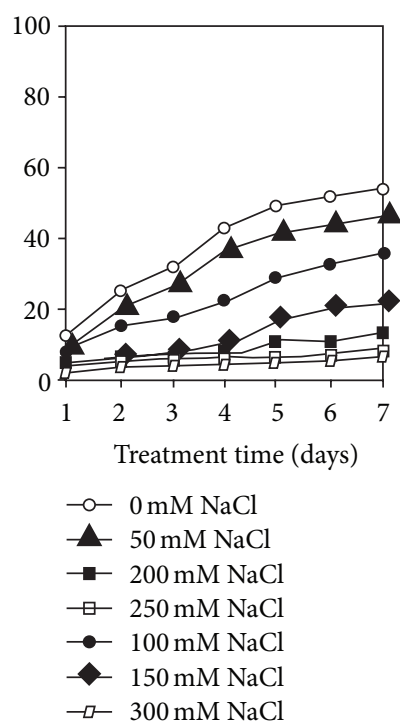

(h) Atriplex isatidea

FIGURE 1: Changes in germination rates with treatment days at different $\mathrm{NaCl}$ concentrations.

TABLE 3: Germination indexes of 8 halophyte seeds at different $\mathrm{NaCl}$ concentrations.

\begin{tabular}{|c|c|c|c|c|c|c|c|}
\hline \multirow{2}{*}{ Species } & \multicolumn{7}{|c|}{ Germination index } \\
\hline & $0 \mathrm{mM}$ & $50 \mathrm{mM}$ & $100 \mathrm{mM}$ & $150 \mathrm{mM}$ & $200 \mathrm{mM}$ & $250 \mathrm{mM}$ & $300 \mathrm{mM}$ \\
\hline S. cannabina & $28.7 \pm 4.10$ & $13.3 \pm 2.71$ & $11.5 \pm 2.35$ & $9.6 \pm 1.60$ & $7.8 \pm 1.64$ & $0.0 \pm 0.00$ & $0.0 \pm 0.00$ \\
\hline L. bicolor & $36.4 \pm 3.51$ & $32.0 \pm 3.68$ & $18.4 \pm 3.80$ & $6.7 \pm 1.09$ & $1.4 \pm 0.12$ & $0.0 \pm 0.00$ & $0.0 \pm 0.00$ \\
\hline S. salsa & $89.2 \pm 4.25$ & $84.8 \pm 4.60$ & $81.6 \pm 3.69$ & $77.1 \pm 2.94$ & $50.3 \pm 4.24$ & $42.4 \pm 3.14$ & $21.5 \pm 2.65$ \\
\hline T. chinensis & $98.3 \pm 0.87$ & $95.6 \pm 1.15$ & $94.1 \pm 2.00$ & $84.7 \pm 5.31$ & $55.4 \pm 7.51$ & $49.4 \pm 2.40$ & $36.7 \pm 3.78$ \\
\hline A. venetum & $65.2 \pm 1.93$ & $61.7 \pm 3.77$ & $59.5 \pm 1.71$ & $45.0 \pm 5.13$ & $38.5 \pm 4.67$ & $33.5 \pm 3.07$ & $21.1 \pm 4.25$ \\
\hline S. europaea & $34.0 \pm 5.33$ & $28.4 \pm 4.15$ & $30.9 \pm 4.72$ & $26.8 \pm 3.02$ & $25.4 \pm 2.34$ & $21.8 \pm 4.37$ & $18.8 \pm 3.64$ \\
\hline P. australis & $19.7 \pm 4.55$ & $17.9 \pm 4.62$ & $13.6 \pm 3.68$ & $4.4 \pm 3.07$ & $1.5 \pm 1.09$ & $0.1 \pm 0.21$ & $0.0 \pm 0.00$ \\
\hline A. isatidea & $11.8 \pm 2.11$ & $8.1 \pm 1.17$ & $9.0 \pm 1.82$ & $5.5 \pm 1.05$ & $4.2 \pm 0.30$ & $1.7 \pm 0.34$ & $0.4 \pm 0.09$ \\
\hline
\end{tabular}

Values are means \pm SE $(n=5)$.

rate for different halophytic species. At $50 \sim 100 \mathrm{mM} \mathrm{NaCl}$ the relative growth rates of Tamarix chinensis and Salicornia europaea increased gradually with an increase in salinity and were greater than those of the control plants (Figure 2).

There was also a certain increase in relative growth for Suaeda salsa at less than $200 \mathrm{mM} \mathrm{NaCl}$ as well as for Limonium bicolor exposed to $50 \mathrm{mM} \mathrm{NaCl}$ compared with the control treatment, which showed that low salt stress could promote the seedling growth of some halophytes. And within the scope of this treatment, all the halophytes examined in this study did not show apparent symptoms of salt injury for their salt-tolerant ability at the seedling stage, except for the fact that two halophytes, Sesbania cannabina and Phragmites australis, presented some symptoms of salt 
TABLE 4: Correlation between relative germination index of eight halophyte seeds and salt concentration.

\begin{tabular}{|c|c|c|c|c|c|c|}
\hline \multirow{2}{*}{ Species } & \multirow{2}{*}{ Regression equation } & \multirow{2}{*}{$\begin{array}{c}\text { Regression } \\
\text { coefficient }\left(R^{2}\right)\end{array}$} & \multirow{2}{*}{$\begin{array}{c}\text { Correlated } \\
\text { coefficient }(r)\end{array}$} & \multicolumn{3}{|c|}{ Salt tolerance $(\mathrm{mM} \mathrm{NaCl})$} \\
\hline & & & & $A$ & $B$ & C \\
\hline S. cannabina & $y=-0.2576 x+78.15$ & 0.8492 & $-0.9215^{* *}$ & 12.2 & 109.3 & 206.3 \\
\hline L. bicolor & $y=-0.2210 x+89.63$ & 0.8316 & $-0.9119^{* *}$ & 66.2 & 179.3 & 292.4 \\
\hline S. salsa & $y=-0.2557 x+109.91$ & 0.9078 & $-0.9528^{* *}$ & 136.5 & 234.3 & 332.1 \\
\hline T. chinensis & $y=-0.2297 x+109.18$ & 0.9099 & $-0.9539^{* *}$ & 148.8 & 257.6 & 366.5 \\
\hline A. venetum & $y=-0.2287 x+104.31$ & 0.9633 & $-0.9815^{* *}$ & 128.2 & 237.5 & 346.8 \\
\hline S. europaea & $y=-0.2349 x+98.52$ & 0.9141 & $-0.9561^{* *}$ & 100.1 & 206.6 & 312.9 \\
\hline P. australis & $y=-0.3875 x+99.48$ & 0.9107 & $-0.9543^{* *}$ & 63.2 & 127.7 & 192.2 \\
\hline A. isatidea & $y=-0.3332 x+97.57$ & 0.9518 & $-0.9756^{* *}$ & 67.7 & 142.7 & 217.8 \\
\hline
\end{tabular}

Note: ${ }^{* *}$ denotes significant at $\leq 0.01$ level. In the regression equation, $y$ is relative germination index, and $x$ is salt concentration. $A$ : appropriate value of salt concentration for seed germination; $B$ : critical value of salt concentration for seed germination; $C$ : limited value of salt concentration for seed germination.

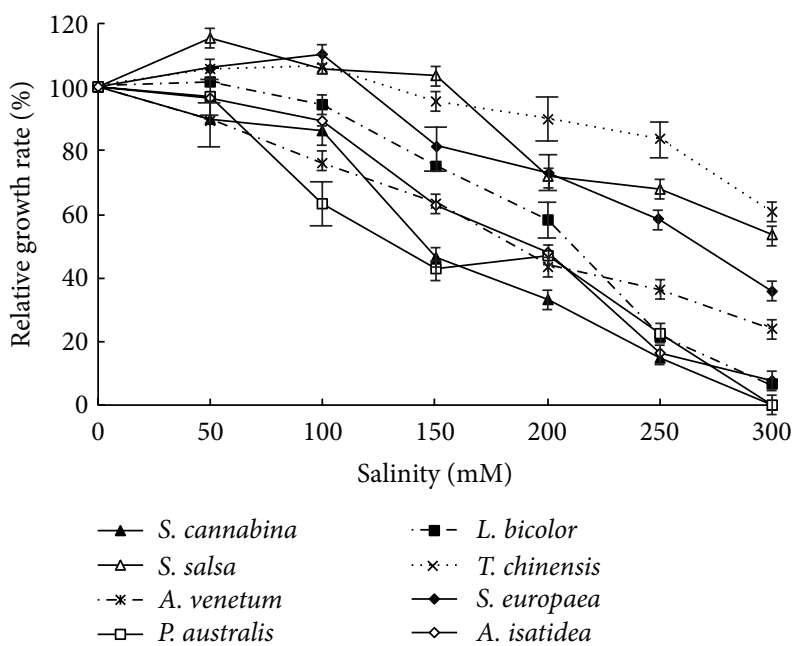

(a) Plant height

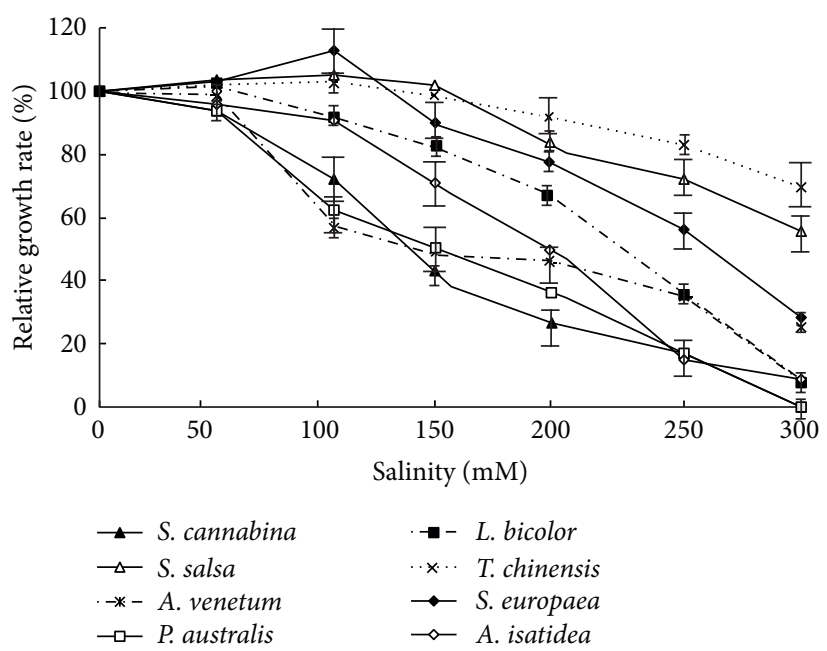

(b) Above-ground biomass

FIGURE 2: Relative growth rate of the eight halophytes after 5-week exposure to different salt concentrations. Each point represents the mean value $\pm \mathrm{SD}$.

injury (leaf margin scorch, leaf turning yellow, and falling off) and a more growth inhibition in relative terms under $150 \mathrm{mM} \mathrm{NaCl}$ treatment (Figure 3). This again indicated that different halophytes responded differently to $\mathrm{NaCl}$ treatment.

The above results showed that the salt tolerance of eight halophyte seedlings were different from each other. Among them, Sesbania cannabina had the lowest salt tolerance, whose average relative growth rate was just $49.1 \%$ with the average salt-injury rate of $41.9 \%$, while Tamarix chinensis had the highest salt tolerance as compared to the other seven species in salt treatments, whose average relative growth increment was as high as $91.1 \%$, only accompanied by the average salt-injury rate of $5.7 \%$ (Table 5). On the basis of their performance in relative growth and salt-injury rate (Figures 2 and 3, Table 5), in all the tested halophytes, the sequence of salt tolerance from strong to weak was as follows: Tamarix chinensis, Suaeda salsa, Salicornia europaea, Limonium bicolor, Atriplex isatidea, Apocynum venetum, Phragmites australis, and Sesbania cannabina.

\section{Discussion}

Screening of available halophytes for salinity tolerance is of considerable value for the economic utilization of saltaffected soils in coastal tidal-flat areas. To explore salt tolerance of 8 halophyte species at the germination and seedling stages was examined in our study. In the germination experiment, salt stress markedly induced lower germination rate and germination index of the eight halophyte seeds (Tables 1 3, Figure 1). For instance, for halophytes Atriplex isatidea, Phragmites australis, Sesbania cannabina, and Limonium bicolor, at $300 \mathrm{mM} \mathrm{NaCl}$, only less than $5 \%$ seeds germinated, and their germination indexes were also nearly $0 \%$ (Table 3 ). This showed that germination of some halophyte seeds might be completely inhibited under high salt conditions. Similar results were also determined in some species of Reaumuria trigyna [19], Aeluropus lagopoides [20], and Salsola vermiculata [8].

A significant and negative correlation was found between data for relative germination index and $\mathrm{NaCl}$ concentration 


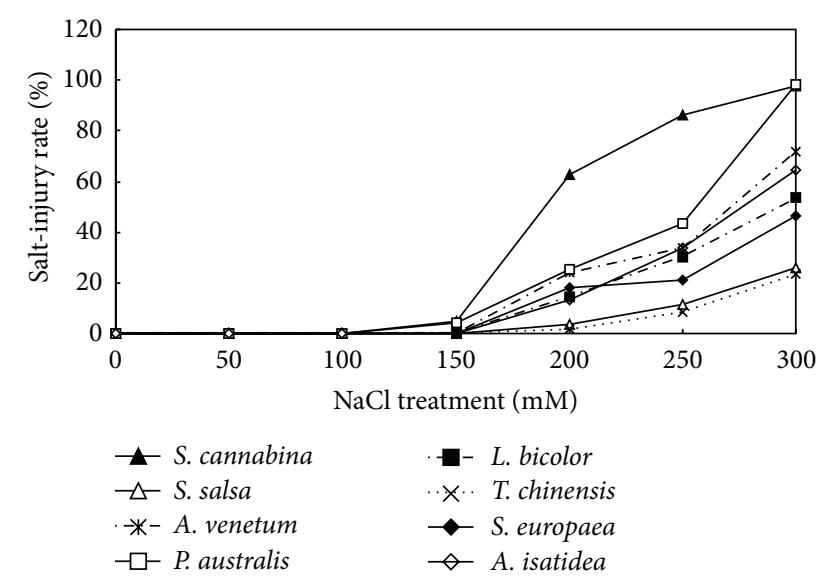

FIGURE 3: Salt-injury rate (\%) of the eight halophytes after 5-week growth in different salt concentrations.

(Table 4). The higher the $\mathrm{NaCl}$ concentration, the lower the germination index of halophytes (Table 3 ). The decrease in ability of halophytes to germinate under salinity conditions was probably due to a reversible osmotic effect that induced dormancy by saline stress [21]. The germinability of halophytes at salinity stress was reported by Chen et al. [22], who found that the germination rate of Apocynum venetum seeds increased with $\mathrm{NaCl}$ concentrations below $150 \mathrm{mM}$, implicating that low salt stress could promote the seed germination of halophytic species. In this experiment, however, the germination of tested halophyte seeds decreased even if the $\mathrm{NaCl}$ concentration was low (Figure 1, Table 3), except for the fact that $50 \mathrm{mM} \mathrm{NaCl}$ had a slight promotion to germination of Suaeda salsa on the second day of the salt treatment (Figure 1(c)). The reasons for the discrepancy between our result and result reported by Chen et al. [22] could be attributed to two aspects. Firstly, low salt stress might inhibit seed germination of halophytes as well as break the seed dormancy, eventually promoting seed germination. Secondly, Chen et al. [22] only considered germination rate under salinity stress regardless of germination index reflecting both the number of germinated seeds and the speed of seed germination while assessing the salt tolerance at germination. Thus, it was likely to overestimate the salt tolerance of halophyte seeds, as there was an evidence to show that, according to regression equation between seed germination and salt concentration, the appropriate, critical, and ultimate salinity for seeds germination calculated using germination index was less than the corresponding values calculated by relative germination rate [23]. Therefore, although germination rate/relative germination rate has been widely used as an index to determine effects of salt stress on the seed germination, it is not likely that this measurement is appropriate to screen halophytes for salt tolerance.

It has been reported that, regardless of the salt concentration used, salt stress had different degrees of inhibition on the growth of plants $[15,24,25]$. The typical symptom of salinity injury to the plant is the growth retardation, leaf shrink with yellow, and shedding or death, due to the inhibition of cell elongation [26]. In the present study, at the seedling stage,
TABLE 5: Mean salt-injury rate and mean relative growth rate of the eight halophytes after 5-week exposure to different salt concentrations.

\begin{tabular}{lcc}
\hline Species & $\begin{array}{c}\text { Mean salt-injury } \\
\text { rate (\%) }\end{array}$ & $\begin{array}{c}\text { Mean relative growth } \\
\text { rate (\%) }\end{array}$ \\
\hline S. cannabina & 41.9 & 49.1 \\
L. bicolor & 16.3 & 63.7 \\
S. salsa & 6.8 & 86.4 \\
T. chinensis & 5.7 & 91.1 \\
A. venetum & 21.6 & 52.3 \\
S. europaea & 14.3 & 77.1 \\
P. australis & 28.6 & 51.3 \\
A. isatidea & 18.7 & 54.1 \\
\hline
\end{tabular}

Note: the mean relative growth rate here was above-ground biomass.

low concentrations of $\mathrm{NaCl}$ promoted the seedlings growth of four species, Tamarix chinensis, Suaeda salsa, Salicornia europaea, and Limonium bicolor (Figure 2), and the eight halophytes, except for Sesbania cannabina and Phragmites australis, showed no apparent symptoms of salt injury within $50 \sim 150 \mathrm{mM} \mathrm{NaCl}$ (Figure 3), indicating no significant effects of low salt stress on the growth of halophytes mentioned above. Similar performances at low salinity were also found in Puccinellia tenuiflora [27] and Atriplex centralasiatica [28]. For example, Qi et al. [29] and $\mathrm{Li}$ et al. [30] found that the growth of Suaeda salsa increased significantly with $\mathrm{NaCl}$ concentrations when exposed to hyposaline environment $(<150 \mathrm{mM} \mathrm{NaCl}) . \mathrm{NaCl}$ solution with high concentration $(>150 \mathrm{mM} \mathrm{NaCl})$ caused a reduction in growth and an increase in salt-injury rate of all tested halophytes due to salt stress (Figures 2 and 3). However, the degree of growth inhibition of halophyte species varied at high $\mathrm{NaCl}$ concentration. For example, the salt tolerance of Sesbania cannabina was the worst in all the tested species, and its individual plant was almost dead after 35 days of $300 \mathrm{mM} \mathrm{NaCl}$ treatment. In contrast, Tamarix chinensis had the highest salt tolerance; regardless of severity of the salt stress, the relative growth increment remained above 65\% (Figure 2) with the average salt-injury rate of $5.7 \%$ (Table 5). The inconsistencies existed in salt tolerance among halophytes, which were possibly due to differences in interspecies metabolic rates and sensitivities of different halophytes to salt stress.

Why could low salt stress promote the growth of plant? There were two possible reasons for this. Firstly, halophytes have a nutritional requirement for sodium and an optimal salt concentration during the process of growth (halophyte cannot complete its life cycle for the lack of $\mathrm{Na}$ ). When the salt concentration in the external solution of plants was less than the optimal salt concentration of halophytes, the increasing of external salinity would probably reduce cell osmotic potential of most halophytes, resulting in the enhancement of water-absorption ability of plant and thereby stimulating the growth of seedlings. Secondly, this may be an adaptation of halophytes to salt stress by accelerating growth in order to reduce the salt concentration [31]. 
As for the inhibition of high salt stress on growth of halophytes, it could be attributed to decreases in cell metabolism and the toxicity of $\mathrm{Na}^{+}$that caused irreversible damage due to prolonged exposure to high concentrations of $\mathrm{NaCl}$ [32]. It is generally accepted that, under high salinity conditions, high sodium concentrations in the external solution of plant cells will produce a variety of negative consequences [33]. As only $\mathrm{NaCl}$ was used in this study, high salinity might very well lead to ionic imbalance, with excess $\mathrm{Na}^{+}$and $\mathrm{Cl}^{-}$ions having a continual damage on function and structure of cell membrane and leading to membrane dysfunction and cell death $[34,35]$. On the other hand, due to the competition for absorptions of $\mathrm{Na}^{+}, \mathrm{K}^{+}, \mathrm{Cl}^{-}$, and $\mathrm{Ca}^{2+}$ to outer membrane, excess $\mathrm{Na}^{+}$and $\mathrm{Cl}^{-}$ions interfered with plants absorption of potassium and calcium and resulted in deficiencies of nutritional elements such as $\mathrm{K}^{+}$and $\mathrm{Ca}^{2+}$ in plants $[36,37]$, affecting the growth and development of plants. High salinity also inflicted hyperosmotic shock on plants, as chemical activity of water was decreased, causing a loss of cell turgor. In addition, salt stress generated an increase in reactive oxygen species (ROS), which leaded to decreases in plant photosynthetic capacity [38]. Despite the absence of data of salt stress effects on leaf photochemistry in this study, the fact that $\mathrm{NaCl}$ treatment caused a very significant reduction in net $\mathrm{CO}_{2}$ assimilation, being closely correlated with biomass and plant height, has been proven [39]. Therefore, it appeared that stomatal limitation of photosynthesis was an important factor reducing halophytes growth in saline conditions. Owing to such factors, tested halophytes in this study demonstrated reduced growth at high salinity (Figure 2 ).

\section{Conclusion}

Perfectly, results in this study indicated that the eight halophytes had different responses to salt stress at the two initial growth stages. Tamarix chinensis and Suaeda salsa produced significantly greater above-ground biomass in relative terms and had a higher germination capacity and a lower saltinjury rate than all the other halophytes. Therefore, Tamarix chinensis and Suaeda salsa were categorized as the most salt tolerant among the eight halophytes appraised. Although the tolerance observed in the present study may or may not be conferred at the adult stage, the performance of seedlings under saline conditions has been considered highly predictive of the response of adult plants to salinity. Thus, the highly salt-tolerant halophytes found in this study would be of considerable economic value for improvement of the heavily saline soils and increasing yield on salt-affected soils in coastal areas. However, the tolerance of halophytes to $\mathrm{NaCl}$ single salt only at the germination and seedling stages was investigated in this study. Thus, it is obvious that further field experiment is required to identify exactly the salt tolerance of the eight halophytes at the adult stage.

\section{Acknowledgments}

The authors wish to acknowledge the support of the research work by the Science and Technology Development Plan of
Yantai (2010163), Natural Science Foundation of Shandong Province (ZR2011DM007), and Key Laboratory Foundation of Soil and Water Conservation and Environmental Protection in Shandong Province (STKF201004).

\section{References}

[1] Z. Chen, I. Newman, M. Zhou, N. Mendham, G. Zhang, and S. Shabala, "Screening plants for salt tolerance by measuring $\mathrm{K}^{+}$ flux: a case study for barley," Plant, Cell and Environment, vol. 28, no. 10, pp. 1230-1246, 2005.

[2] K. C. Ravindran, K. Venkatesan, V. Balakrishnan, K. P. Chellappan, and T. Balasubramanian, "Restoration of saline land by halophytes for Indian soils," Soil Biology and Biochemistry, vol. 39, no. 10, pp. 2661-2664, 2007.

[3] T. J. Flowers, A. Garcia, M. Koyama, and A. R. Yeo, "Breeding for salt tolerance in crop plants - the role of molecular biology," Acta Physiologiae Plantarum, vol. 19, no. 4, pp. 427-433, 1997.

[4] S. C. Praxedes, C. de Lacerda, F. M. DaMatta, J. T. Prisco, and E. Gomes-Filho, "Salt tolerance is associated with differences in ion accumulation, biomass allocation and photosynthesis in cowpea cultivars," Journal of Agronomy and Crop Science, vol. 196, no. 3, pp. 193-204, 2010.

[5] T. Zhang, S. Zeng, Y. Gao et al., "Assessing impact of land uses on land salinization in the Yellow River Delta, China using an integrated and spatial statistical model," Land Use Policy, vol. 28, no. 4, pp. 857-866, 2011.

[6] H. Fang, G. Liu, and M. Kearney, "Georelational analysis of soil type, soil salt content, landform, and land use in the Yellow River Delta, China," Environmental Management, vol. 35, no. 1, pp. 72-83, 2005.

[7] Q. Ye, G. Liu, G. Tian et al., "Geospatial-temporal analysis of land-use changes in the Yellow River Delta during the last 40 years," Science in China D, vol. 47, no. 11, pp. 1008-1024, 2004.

[8] I. R. Guma, M. A. Padrón-Mederos, A. Santos-Guerra, and J. A. Reyes-Betancort, "Effect of temperature and salinity on germination of Salsola vermiculata L. (Chenopodiaceae) from Canary Islands," Journal of Arid Environments, vol. 74, no. 6, pp. 708-711, 2010.

[9] J. C. Dagar, "Ecology, management and utilization of halophytes," Bulletin of the National Institute of Ecology, vol. 15, no. 1, pp. 81-89, 2005.

[10] M. A. Khan and K. H. Sheith, "Effects of different levels of salinity on seed germination and growth of Capsicum annuum," Biology Journal, vol. 22, no. 1, pp. 15-16, 1996.

[11] Y. Zeng, Z. Cai, J. Ma, F. Zhang, and B. Wang, "Effects of salt and water stress on seed germination of halophytes Kalidium foliatum and Halostachys caspica," Chinese Journal of Ecology, vol. 25, no. 9, pp. 1014-1018, 2006.

[12] M. C. Shannon and C. L. Noble, "Genetic approaches for developing economic salt tolerant crops," in Agricultural Salinity Assessment and Management, K. K. Tanji, Ed., ACSE Manuals and Reports on Engineering Practice No. 71, p. 161, ASCE, New York, USA, 1990.

[13] T. J. Flowers and A. R. Yeo, "Breeding for salinity resistance in crop plants: where next?" Australian Journal of Plant Physiology, vol. 22, no. 6, pp. 875-884, 1995.

[14] S. Krishnaraj, B. T. Mawson, E. C. Yeung, and T. A. Thorpe, "Utilization of induction and quenching kinetics of chlorophylla fluorescence for in vivo salinity screening studies in wheat (Triticum aestivum vars Kharchia 65 and Fielder)," Canadian Journal of Botany, vol. 71, no. 1, pp. 87-92, 1993. 
[15] S. Sevengor, F. Yasar, S. Kusvuran, and S. Ellialtioglu, “The effect of salt stress on growth, chlorophyll content, lipid peroxidation and antioxidative enzymes of pumpkin seedling," African Journal of Agricultural Research, vol. 6, no. 21, pp. 4920-4924, 2011.

[16] M. A. Khan and I. A. Ungar, "Seed polymorphism and germination responses to salinity stress in Atriplex triangularis Willd," American Journal of Botany, vol. 71, pp. 481-489, 1984.

[17] SAS Institute Inc, SAS/STAT 9. 2 User's Guide, SAS Institute, Cary, NC, USA, 2008.

[18] Y. E. Bai, J. Yi, A. L. Gu, and Z. J. Guo, "Studies on salt tolerance of seeds of 8 rhizomatous grasses," Grassland of China, vol. 21, no. 2, pp. 55-59, 2005 (Chinese).

[19] Y. Xue and Y. Wang, "Influence of light, temperature and salinity on seed germination of Reaumuria trigyna Maxim," Plant Physiology Communications, vol. 43, no. 4, pp. 708-710, 2007.

[20] S. Gulzar and M. A. Khan, "Seed germination of a halophytic grass Aeluropus lagopoides," Annals of Botany, vol. 87, no. 3, pp. 319-324, 2001.

[21] M. Mehrun-Nisa, M. A. Khan, and D. J. Weber, "Dormancy, germination and viability of Salsola imbricata seeds in relation to light, temperature and salinity," Seed Science and Technology, vol. 35, no. 3, pp. 595-606, 2007.

[22] Y. Y. Chen, G. Q. Li, J. Meng, and J. M. Cao, "Effect of sodium chloride stress to the seed germination and seedling growth of Apocynum venetam L.," Chinese Wild Plant Resources, vol. 26, no. 2, pp. 49-51, 2007 (Chinese).

[23] D. H. Yu, "Effects of $\mathrm{NaCl}$ stress on the seed germination and seedling growth of Limonium Bicolor," Journal of Huazhong Normal University, vol. 42, no. 3, pp. 435-439, 2008 (Chinese).

[24] S. Kusvuran, S. Ellialtioglu, F. Yasar, and K. Abak, "Effects of salt stress on ion accumulation and activity of some antioxidant enzymes in melon (Cucumis melo L.)," Journal of Food, Agriculture and Environment, vol. 2, no. 5, pp. 351-354, 2007.

[25] H. Y. Dasgan and S. Koc, "Evaluation of salt tolerance in common bean genotypes by ion regulation and searching for screening parameters," Journal of Food, Agriculture and Environment, vol. 7, no. 2, pp. 363-372, 2009.

[26] F. Yasar, S. Ellialtioglu, and K. Yildiz, "Effect of salt stress on antioxidant defense systems, lipid peroxidation, and chlorophyll content in green bean," Russian Journal of Plant Physiology, vol. 55 , no. 6, pp. 782-786, 2008.

[27] C. W, Yang, D. C. Shi, and Y. Zhang, "Effects of complex salt and alkali conditions on the germination of seeds of Puccinellia tenuiflora," Prataculturae Sinica, vol. 15, no. 5, pp. 45-51, 2006.

[28] C. Z. Li, X. J. Liu, W. Huang, and H. L. Qiao, "Effect of salt stress on seed germination and its recovery of Atriplex centralasiatica," Journal of Agricultural University of Hebei, vol. 28, no. 6, pp. 1-4, 2005 (Chinese).

[29] C. H. Qi, N. Han, and B. S. Wang, "Effect of different salt treatments on succulence of Suaeda salsa seedlings," Chinese Bulletin of Botany, vol. 22, no. 2, pp. 175-182, 2005 (Chinese).

[30] W. Q. Li, X. J. Liu, and K. F. Zhao, "Growth, development and ions distribution of three halophytes under salt stress," Chinese Journal of Eco-Agriculture, vol. 14, no. 2, pp. 49-52, 2006 (Chinese).

[31] B. Mandák and P. Pyšek, "Effects of plant density and nutrient levels on fruit polymorphism in Atriplex sagittata," Oecologia, vol. 119, no. 1, pp. 63-72, 1999.

[32] M. A. Khan and I. A. Ungar, "Effects of light, salinity, and thermoperiod on the seed germination of halophytes," Canadian Journal of Botany, vol. 75, no. 5, pp. 835-841, 1997.
[33] J. Zhu, P. M. Hasegawa, and R. A. Bressan, "Molecular aspects of osmotic stress in plants," Critical Reviews in Plant Sciences, vol. 16, no. 3, pp. 253-277, 1997.

[34] R. Serrano, J. M. Mulet, G. Rios et al., "A glimpse of the mechanisms of ion homeostasis during salt stress," Journal of Experimental Botany, vol. 50, pp. 1023-1036, 1999.

[35] S. Chookhampaeng, "The effect of salt stress on growth, chlorophyll content proline content and antioxidative enzymes of pepper (Capsicum annuum L.) seedling," European Journal of Scientific Research, vol. 49, no. 1, pp. 103-109, 2011.

[36] A. Polle, "Defence against photo-oxidative damage in plants," in Oxidative Stress and Molecular Biology of Antioxidant Defences, J. G. Scandalios, Ed., pp. 623-666, Cold Spring Harbour Laboratories, Cold Spring Harbor, NY, USA, 1997.

[37] O. Borsani, V. Valpuesta, and M. A. Botella, "Evidence for a role of salicylic acid in the oxidative damage generated by $\mathrm{NaCl}$ and osmotic stress in Arabidopsis seedlings," Plant Physiology, vol. 126, no. 3, pp. 1024-1030, 2001.

[38] A. Price and G. Hendry, "Iron catalysed oxygen radical formation and its possible contribution to drought damage in nine native grasses and three cereals," Plant, Cell \& Environment, vol. 14, no. 5, pp. 477-484, 1991.

[39] L. Shabala, T. McMeekin, and S. Shabala, "Osmotic adjustment and requirement for sodium in marine protist thraustochytrid," Environmental Microbiology, vol. 11, no. 7, pp. 1835-1843, 2009. 


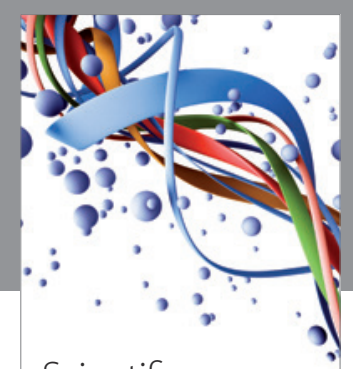

Scientifica
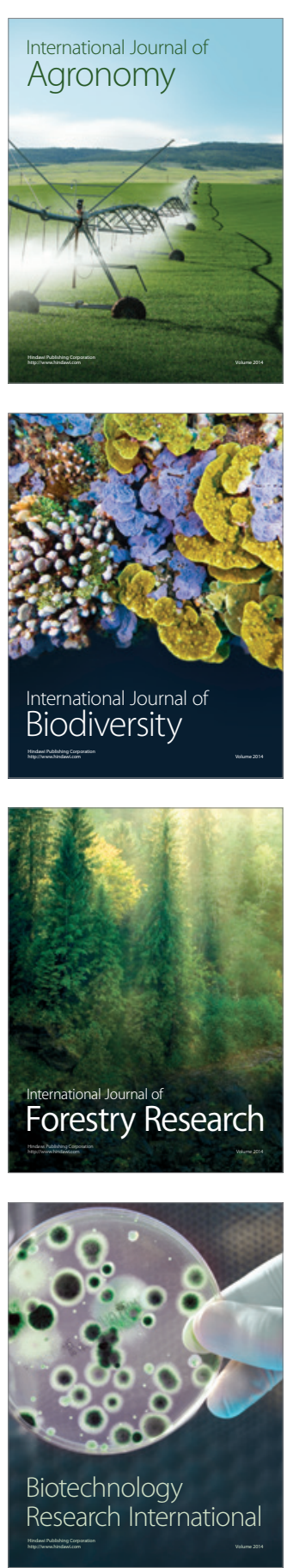
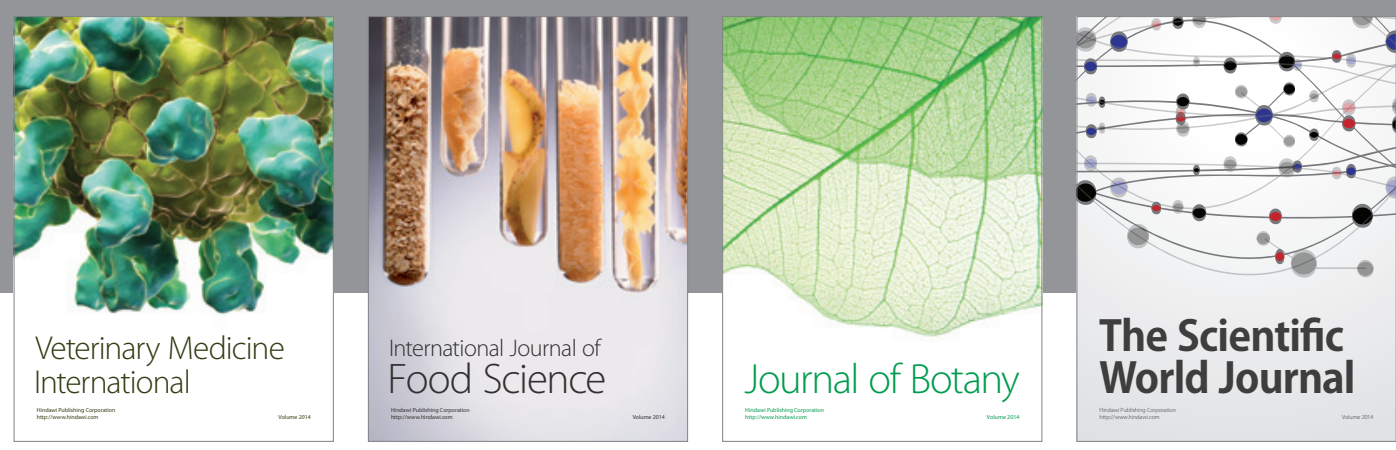

The Scientific World Journal
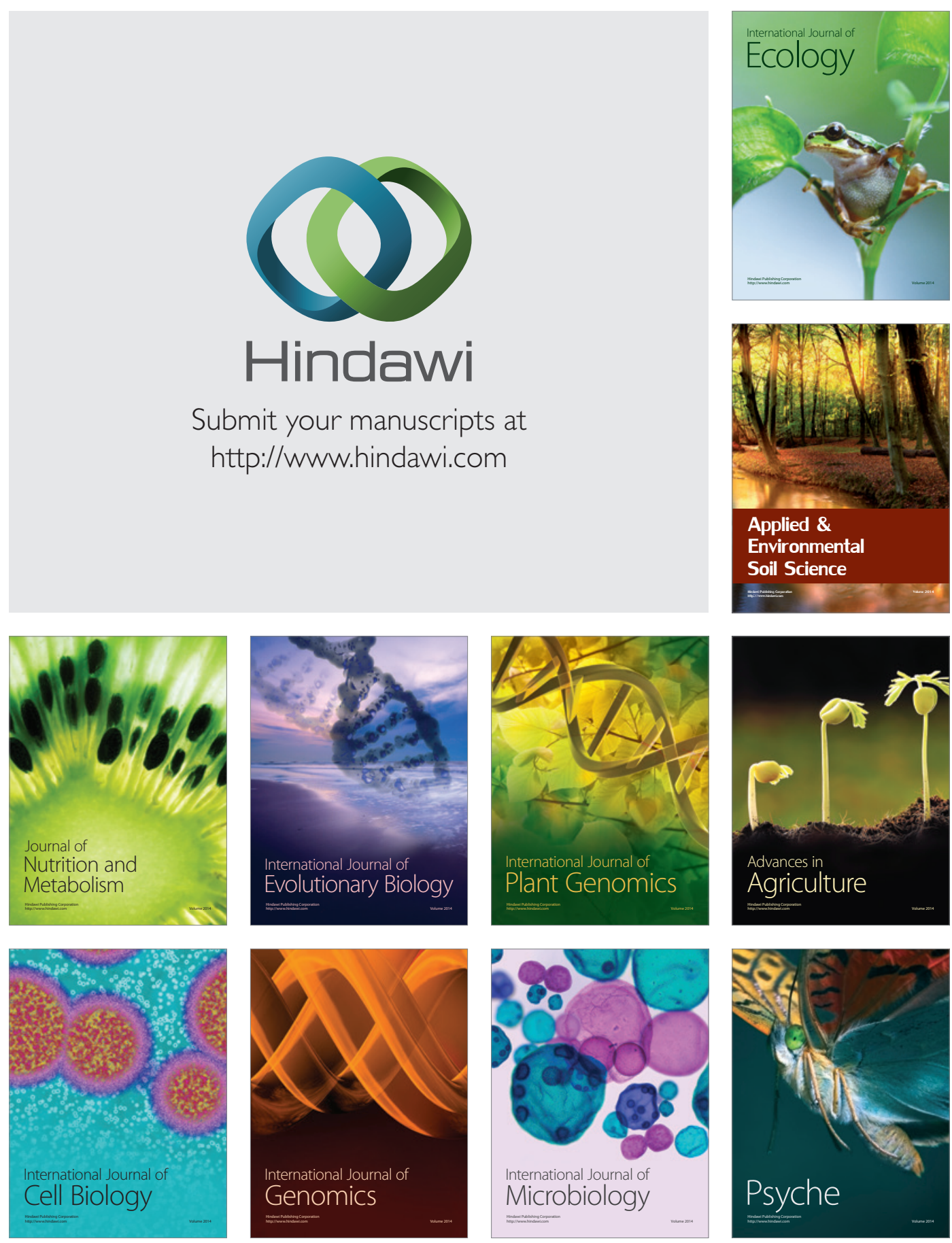